\title{
The Connotation, Attribution and Evasion of Employees' Misconduct
}

\author{
Kefeng Li \\ School of Business, Anyang Normal University, Anyang, China \\ Email: chengf_tina@163.com
}

How to cite this paper: Li, K. F. (2017). The Connotation, Attribution and Evasion of Employees' Misconduct. Creative Education, 8, 2501-2507.

https://doi.org/10.4236/ce.2017.815172

Received: December 7, 2017

Accepted: December 23, 2017

Published: December 26, 2017

Copyright $\odot 2017$ by author and Scientific Research Publishing Inc. This work is licensed under the Creative Commons Attribution-NonCommercial International License (CC BY-NC 4.0). http://creativecommons.org/licenses/by-nc/4.0/

\begin{abstract}
Employees' misconduct is a kind of behavior that infringes common interests for individual interests. Under the influence of interest motivation, fluke mind, and management loopholes, employees' misconduct is very common in the organization. In order to avoid employees' misconduct, comprehensive measures should be taken in the aspects of law, regulation system, organizational culture and so on.
\end{abstract}

\section{Keywords}

Misconduct, Collusion, Fluke Mind, Evasion

\section{The Connotation of Misconduct}

The term misconduct stems from criminology. Employee misconduct refers to employees' subjective behaviors that have obvious harm to the members, organizational survival and organizational rules in various situations. It is a kind of behavior that infringes common interests for individual interests, including minor acts such as lying, laziness and scamming. It also includes such serious acts as theft, fraud, vandalism and corruption. Both expert findings and real-world experience show that employee misconduct is prevalent, with $35 \%-55 \%$ of employees having behavior such as theft, embezzlement, sabotage and absenteeism (Zeitlin, 1971) and 79\% of employees having temper tantrums in work (Yang, Nguyen, \& Chen, 2011). According to statistics, employee misconduct and mistakes each year will give employers about 60 - 2000 billion dollars in damages (Sampson, 1987).

In the UK, employee misconduct is commonly referred to as "fiddling" and in the United States as "skimming" or "scamming". The misconduct of members of the organization has a long history. In different stages of historical development 
and organization, such misconduct is ubiquitous, only different in terms of degree and manifestation.

Employee misconduct will bring great negative and passive effects to the corporations, the customers and even the government and society. Employers (bosses), employees, customers (consumers) constitute a common triangle of triangular interest model. In the tripartite relationship, employees act as intermediaries to connect employers and customers: If employees collude with their employers, they will harm the interests of their customers. If they collude with customers, it will damage the interests of employers. Therefore, the key subject of misconduct is the staff; therefore, this article takes the employee's misconduct as the focus of analysis.

\section{Attribution of Employee Misconduct}

Some employee misconduct is in collusion with managers, and some misconduct will be severely punished by management layer. Misconduct may be individually planned and completed by an individual, or as a result of group collaboration. Some employers view employee misconduct as a violation of the organization's image and damage to the organization's interests, regardless of whether the immediate victim is a customer or an employer. If the victim of misconduct is the customer rather than the employer himself, some employers, by default, even encourage employee misconduct. The starting point for most misconduct is for personal gain. However, some acts of misconduct are out of anger or dissatisfaction as a means of combating revenge on leaders, co-workers, organizations, institutions and even government and society, such as deliberately damaging the machinery and equipment of a corporation, and deliberately wasting a large amount of resources or raw materials such as water and electricity, deliberately undermining the country's roads, cables and other facilities. The misconduct has been detrimental to oneself, mostly motivated by anger and retaliation. In general, there are many factors that contribute to the employees' misconduct:

\subsection{Interest Driven}

Interest refers to a series of material and spiritual products that human beings use to satisfy their own desires. To some extent, they include money, power, lust, honor, fame, statehood, territory, sovereignty and even the pleasure form helping others. Anything that satisfies the human desires can be called an interest. The only principle driven by interest is to pursue the maximization of benefits. Driven by interests, employee behavior breaks the regulatory, legal, and moral constraints, and at the same time as it is profitable to himself, undermines the interests of employers, customers or society, thereby creating misconduct.

\subsection{The Use of Authority or Privilege}

If an employee has some authority, privilege, or some other scarce resource that someone else needs, the employee has the condition and the opportunity to 
make profit for himself. For example, during the government bidding or purchasing process, bidders or customers often give bribes to individuals or units that have the power to make decisions. The scandals that unit leaders dominate, their powers are highly centralized, which lead to eating and drinking habits, sending gifts, trading power for money, and trading power for sex are not uncommon.

\subsection{Management and Supervision Loopholes}

If the organization's management rules and regulations are not perfect, lack supervision of the use of power and employees' behavior, then conditions for employee misconduct will be created.

\subsection{The Professional Skills or Expertise}

For example, in the maintenance of machinery and equipment such as automobiles, mobile phones and computers, maintenance personnel use the loopholes in customer's lack of specialized knowledge to cheat and deceive customers with shoddy, old-fashioned, over-the-top prices. In addition, in hospitals, doctors who fail to abide by professional ethics may take advantage of their lack of medical knowledge to over-treat and over-consume patients, and seek undue advantage for doctors and hospitals.

\subsection{Information Asymmetry between the Two Sides}

If the transaction relationship between the two parties occurs only once, the fraudulent transactions are easy to occur. For example, places such as tourist attractions, airports, hotels, restaurants and supermarkets near the station have relatively large floating population. The trading relationship between the two parties is generally only once. Consumers are partly or completely unaware that it is easy for sellers who have mastered all the information about goods or service to cheat consumers with shoddy, trade-in, or fake goods. Even if consumers finally find themselves cheated, but the debt collection and right maintenance costs are relatively high, at last they often give up it. In recent years, many well-known tourist attractions in our country emerge meals which cost enormous price and other fraud, which the local government has repeatedly forbidden, with little effect. Because the cost of such misconduct is small, the profits are great, so it is difficult to put an end to it completely.

\subsection{Cooperation Collusion}

The triangular relationship between employers, employees and customers is a typical feature of the service industry. Any two of the three may work in collusion with each other to form a community of interests and profit themselves by infringement on the interests of the third party. Colluding employers with employees may infringe the interests of customers. Employees' cooperation with customers may hinder the interests of employers. Employers may also satisfy 
themselves and their customers by deducting employees' wages and bonuses. In particular, it is most common for employers and employees to collude with each other to violate with the interests of consumers because, in comparison, the connection between the interests of employers and employees is more and more likely to become allied to their interests. For example, employers and employees work together to raise prices unilaterally, use shoddy, confused products, conceal their defects, exaggerate their merits, and so on.

\subsection{Fluke Mind}

With luck, some employees may take the risk and do something unfavorable to their customers or employers. The misconduct of employees is generally affected by the chances of being lucky. As mentioned above, the phenomenon of cheating and selling in the vicinity of a station, the abuse of power for personal gains, etc., have been influenced by fluke mind. If you anticipate that your misconduct will be detected and severely punished, the likelihood of misconduct will be reduced.

\subsection{The Penalties and Even the Default or Encouragement of the Staff Misconduct from the Organization}

Organizations that turn a blind eye or impose punitive sanctions or even acquiesce or encourage employees' misdeeds can undoubtedly promote employees' misconduct. In fact, if the illegal, disciplinary violation and non-compliance are not punished, that will promote encouragement in disguise.

\subsection{Revenue from Misconduct Is Greater Than Its Cost}

Employees have to pay for their misdeeds, that is, there is a cost of misconduct, if the profit of misconduct is bigger than its cost, then under the balance, employees are likely to take the risk. And the greater the difference between benefits and costs is, the greater the probability of misconduct and the extent of its harm will be.

The criteria and basis of the above attribution analysis are not absolute and uniform, with classification from different perspectives and different focuses, so some classification may be cross-cutting or overlapping. And in reality, employees' misconduct is often the result of the combination of the above factors, and the factors that cause the misconduct of employees cannot be simply and completely classified as a single factor.

\section{The Evasion of Staff Misconduct}

Staff misconduct, in the short term, offers them some personal gains, but it damages the interest of the units, consumers, government and society. But in the long run, employees themselves may not be the ultimate beneficiaries. The ultimate result of misconduct is likely to be no real beneficiary. If the customer's interests are compromised, then the choice may be a complaint, a refusal to buy or sell next time, spreading the organization's fraud, etc. Ultimately the victims will 
be the organization and the employees themselves. An employer's choice may be to raise the price of a product or service, to lower the wage of a worker, to increase his labor intensity, to prolong the working hours, to increase penalties, if the employer's interests are harmed and the profits of the employer are reduced, which in turn would increase the costs and so on, so the ultimate victim will also be the employee himself and the consumer. If employees damage public property, infrastructure, etc., the victims will be the general public, including the employees themselves. Therefore, we must find ways to sidestep employee misconduct. Specifically speaking, it includes the following aspects:

\subsection{Taking Precautions and Taking Preventive Measures}

Disease prevention is always less costly than treatment and so is organizational management, and prevention mechanisms are always more important than punishment system. Employee misconduct often means the existence of organizational management loopholes. Therefore, taking precautions, finding the problems and loopholes in organizational management and system so as to modify, improve, block the path of employee deviations, and prevent misconduct in tine, is the first step that any organization must do.

\subsection{Remedying the Situation in Order to Never Suffer}

Organizational structure is reasonable, the system is perfect, the management is scientific, staffs' unruly behavior still cannot be completely avoided. If employee misconduct has occurred or cannot be avoided, the organization should take remedial measures to prevent the recurrence of similar acts. Objectively speaking, the various efforts made by the organization to prevent and control employee misconduct are actually the "tuition fees" that organizations must pay during the process of their growth. They are the factors that make the organization from small to big, from weak to strong, from imperfect to gradually perfect, which need pay the cost and price. From the inside of the organization, the organization develops and perfects constantly in the game with the staff. To some extent, the unruly behavior of employees is also an indispensable catalyst for the healthy growth of the organization, and is one of the driving forces for the development of the organization.

\subsection{Strict Regulations and Heavy Punishment on Offenders}

Employees' misconduct will seriously damage the interests of employers and customers, and even harm the interests of the government and the public. Therefore, the organization must have strict rules and regulations and severely punish employees for misconduct, such as demotion, salary reduction, dismissal and even prosecution, in order to raise the costs and price of employee misconduct. Because judging from the cost-benefit relationship, employee misconduct is a typical self-interest behavior, for employees, who get benefits; misconduct time, tools, efforts, fear, and punishment, etc., are the cost and price of miscon- 
duct. If the benefits of misconduct are greater than their costs and are profitable, the incidence of misconduct is inevitable; if the profits of proceeds are less than its cost, or the balance of payments is unprofitable, then the probability of misconduct will be much greater reduced, or even basically eliminated. Therefore, an important measure to reduce or even avoid misconduct is to formulate a strict, rigorous and severe punishment system to raise the costs and price of misconduct as much as possible so that employees will pull back in the face of their own desires and selfish interests.

\subsection{The Correct Guidance and Reasonable Vent}

The starting point for most employees' misconduct is undoubtedly self-serving, but some of the misconduct is out of anger or dissatisfaction as a means of combating retaliation against employers, companies, institutions and even government and society. For example, some employees deliberately damage the machinery and equipment of a unit and deliberately waste resources such as water, electricity and other raw materials on purpose and deliberately destroy the country's roads, cables and other facilities. Such misconduct has been detrimental to the public. Most of its motives are out of anger and revenge in order to vent its pressure and dissatisfaction. Catharsis is an important way to relieve stress and frustration, but catharsis must be reasonable. If it is in violation of the unit rules and regulations, morality and law, which is beneficial to their own advantage, and harmful to the public, such catharsis should be avoided. Therefore, it is very important not to violate the law, not to violate the morals, not to harm oneself and others, and to give ventures in a timely, appropriate and reasonable manner. Due to their dissatisfaction, employees may get the pressure and frustration if they can be properly vent, the incidence of misconduct can be greatly reduced.

\subsection{Corporate Culture, Moisten Things without Sound}

Corporate culture has a profound impact on employees' thinking patterns and behaviors. A healthy and progressive corporate culture will guide employees forward and make employees and enterprises grow together. On the contrary, an unhealthy and negative corporate culture may lead to disorganization, chaotic management and frequent misconduct. Distortion of corporate culture is an important reason for employee misconduct. Many enterprises do not attach importance to the building of enterprise culture, or sloganization, politicization, rigidity, visualization of the corporate culture, cannot fundamentally have a positive impact on the concept and behavior of employees. Some companies even promote negative and unhealthy corporate culture to employees, such as encouraging employees to fake, cheating customers, dishonesty and so on. Many enterprises also listen to the unethical behavior such as sewage disposal and harm to public interest. Some enterprises are unwilling to be responsible for injuries or accidents and even leave employees out of work. Such a corporate cul- 
ture often leads to the frequent occurrence of staff misconduct. Therefore, to create a true, healthy and standard corporate culture is necessary, so as to achieve the effective management of national laws and regulations, social ethics, corporate regulations, corporate culture of the four in one. From top to bottom, from the inside to the outside, this can help to avoid employee misconduct as much as possible by the reasonable, standardized, accurate and effective restrict and guide of the behavior of enterprises and employees.

\section{Conclusion}

Employees' misconduct will seriously damage the interests of the organization, customers and even the government and society. Corresponding management measures should be taken to avoid, prevent and mitigate the misconduct as much as possible to create favorable conditions for the normal operation of the organization.

\section{References}

Sampson, S. L. (1987). The Second Economy of the Soviet Union and Eastern Europe. The Annals of the American Academy of Political and Social Science, 493, 120-136. https://doi.org/10.1177/0002716287493001009

Yang, J., Nguyen, H.-H., \& Chen, X. F. (2011). Study on the Structure Classification of Workplace Deviant Behavior. Journal of Management, No. 3, 403-408.

Zeitlin, L. R. (1971). Stimulus/Response: A Little Larceny Can Do a Lot for Employee Morale. Psychology Today, 14, 22, 24-26, 64. 